\title{
Factors associated with preservation of facial nerve function after surgical resection of vestibular schwannoma
}

\author{
Orin Bloch • Michael E. Sughrue • Rajwant Kaur • \\ Ari J. Kane • Martin J. Rutkowski · Gurvinder Kaur • \\ Isaac Yang • Lawrence H. Pitts • Andrew T. Parsa
}

Received: 15 February 2010/Accepted: 12 July 2010/Published online: 6 August 2010

(C) The Author(s) 2010. This article is published with open access at Springerlink.com

\begin{abstract}
Avoidance of facial nerve palsy is one of the major goals of vestibular schwannoma (VS) microsurgery. In this study, we examined the significance of previously implicated prognostic factors (age, tumor size, the extent of resection and the surgical approach) on post-operative facial nerve function. We selected all VS patients from prospectively collected database (1984-2009) who underwent microsurgical resection as their initial treatment for histopathologically confirmed VS. The effect of variables such as surgical approach, tumor size, patient age and extent of resection on rates facial nerve dysfunction after surgery, were analyzed using multivariate logistic regression. Patients with preoperative facial nerve dysfunction (House-Brackman [HB] score 3 or higher) were excluded, and $\mathrm{HB}$ grade of 1 or 2 at the last follow-up visit was defined as "facial nerve preservation." A total of $624 \mathrm{VS}$ patients were included in this study. Multivariate logistic regression analysis found that only pre-operative tumor size significantly predicted poorer facial nerve outcome for patients followed-up for $\geq 6$ and $\geq 12$ months (OR 1.27, 95\% CI 1.09-1.49, $p<0.01$; OR 1.35, 95\% CI 1.10-1.67, $P<0.01$, respectively). We found no significant relationship between facial nerve function and age, extent of resection, surgical approach, or tumor size (when extent of resection and surgical approach were included in the regression analysis). Because facial nerve palsy is a debilitating and psychologically devastating condition for
\end{abstract}

O. Bloch · M. E. Sughrue - R. Kaur - A. J. Kane ·

M. J. Rutkowski · G. Kaur · I. Yang · L. H. Pitts ·

A. T. Parsa $(\bowtie)$

Department of Neurological Surgery, University of California

at San Francisco, 505 Parnassus Ave, San Francisco,

CA 94143, USA

e-mail: parsaa@neurosurg.ucsf.edu the patient, we suggest altering surgical aggressiveness in patients with unfavorable tumor anatomy, particularly in cases with large tumors where overaggressive resection might subject the patient to unwarranted risk. Residual disease can be followed and controlled with radiosurgery if interval growth is noted.

Keywords Vestibular schwannoma A Acoustic neuroma . Microsurgery $\cdot$ Facial nerve function - Facial nerve palsy

\section{Introduction}

Vestibular schwannoma (VS) is a benign tumor that arises from one or more constituent nerves comprising the eighth cranial nerve complex $[1,2]$. Attempts at surgical removal of these tumors can be complicated by intraoperative damage to the facial nerve and the cochlear nerve, along with other neurological and vascular injuries [1, 3-13]. Even though advances in surgical techniques have improved facial nerve outcomes, functional preservation is still an issue because injury to the facial nerve has significant physical and psychological consequences for the patient [14-16]. It has been suggested that age, tumor size, and surgical approach all can impact ultimate facial functional outcome [16-19].

There are a number of studies in the literature that present the outcome of facial nerve function after VS resection; however, these studies largely are small to modest sized case series [12]. In this study, we prospectively collected facial nerve function data on 624 patients over a course of 25 years. We examined the significance of previously implicated prognostic factors (age, tumor size, the extent of resection and the surgical approach) on the rates of post-operative facial nerve preservation. 


\section{Methods}

Patient population

Clinical, radiographic and audiometric data for all patients evaluated and/or treated for a known or presumed VS by the senior authors (Lawrence H. Pitts and Andrew T. Parsa) at our institution over a 25 year period (1984-2009) were prospectively collected in a database. We retrospectively identified all patients in this database with data relevant to this study undergoing microsurgical resection of VS. Patients with a history of prior microsurgery for VS, or radiosurgery/radiotherapy were excluded. Also, any patient who did not have 6 months of follow-up, including early post-operative death, were excluded from analysis. This study was conducted with the approval of the University of California at San Francisco Committee on Human Research under approval number H41995-32911-01.

\section{Data analysis}

Patient data were collected prospectively. In all cases, intraoperative direct stimulation of the tumor surface, monitored by facial EMG, was used to identify the facial nerve position and function prior to any tumor manipulation and resection. Permanent facial nerve dysfunction was defined as House-Brackman (HB) grade 3 or higher function persisting for greater than 6 months beyond the date of surgery [20].

Tumor size was measured as the largest single preoperative tumor diameter including the intracanalicular portion. The extent of resection was judged by subjective intraoperative impression; however, if an MRI performed within 6 months of surgery demonstrated that this impression was wrong, the extent of resection classification was reclassified to correlate to the MRI findings. Near total resection (NTR) indicates that only of a thin layer of tumor remained on one or more nerves in a conscious attempt to preserve function. If imaging studies revealed gross evidence of residual disease, then it was termed subtotal resection (STR).

\section{Statistical analysis}

In this study, we assessed the relationship between permanent facial nerve palsy and age, tumor size, the extent of resection and the surgical approach. Binary variables were compared using Pearson's $\chi^{2}$ test. Continuous variables were compared using an independent samples $t$-test or ANOVA.

Given statistically significant between group differences in potentially confounding variables, such as tumor size, we performed multivariate regression analysis to study the impact of tumor size, extent of resection, and surgical approach on facial nerve function. Variables which impacted facial nerve outcome with a $P=0.2$ or less on univariate analysis were included in stepwise binary logistic regression modeling [21]. All odds ratios on multivariate analysis, reflect the risk of having facial nerve palsy at 6 month post-operatively. The goodness of fit of the regression model was confirmed by demonstrating a non-significant $P$-value on the Hosmer-Lemeshow test [21, 22].

We tested interaction terms between each of the three variables to significantly impact hearing on univariate analysis. The statistical significance of the interactions was assessed with the use of backward stepwise regression, in which statistical significance was estimated by means of the likelihood-ratio test to assess the effect of removing interaction terms for all strata of the given variable [21]. After finding that none of the interaction terms would significantly (unadjusted $P>0.2$ for all terms) alter the $\log$ likelihood of the regression model if removed, we calculated the adjusted odds ratios without adjusting for interactions for $\geq 6$ months follow-up and $\geq 12$ months follow-up.

Continuous variables are presented as mean $\pm \mathrm{SE}$. Statistical tests were considered significant when the two sided $P<0.05$ after correcting for multiple comparisons using the Bonferroni method. All statistical tests were performed using SPSS version 17.

\section{Results}

Patient population

A total of 624 patients underwent microsurgical resection for acoustic neuroma in this period. About 255 (41\%) patients had facial nerve palsy (HB grade 3 or higher) and $369(59 \%)$ patients had normal facial function (HB grade 1 or 2) 6 months post-operatively. The demographic characteristics of these two groups are compared in Table 1. We also present surgeon comparison which shows insignificant relationship to facial nerve preservation (57 vs. $62 \%$, $P=0.196$; Table 2). The median follow-up for these patients was 37 months, with $64 \%$ patients followed $\geq 12$ months, $37 \%$ patients followed up for $>60$ months and $14 \%$ of patients followed for $>120$ months.

The effect of patient age on facial nerve preservation

The mean patient age was 49.5 years (range 13-80 years) in our study. There was no statistical difference between a patient's age and facial nerve preservation ( $49 \pm 0.79$ years for facial palsy vs. $49 \pm 0.65$ years for normal facial 
Table 1 Clinical characteristics of patients in this series

\begin{tabular}{|c|c|c|c|}
\hline \multirow[t]{2}{*}{$N=624$} & \multicolumn{2}{|c|}{ Facial nerve palsy } & \multirow[t]{2}{*}{$P$-value } \\
\hline & $\begin{array}{l}\text { Yes } \\
255(\%)\end{array}$ & $\begin{array}{l}\text { No } \\
369(\%)\end{array}$ & \\
\hline \multicolumn{3}{|l|}{ Gender } & NS \\
\hline Male & $116(45)$ & $176(47)$ & \\
\hline Female & $139(55)$ & $196(53)$ & \\
\hline Age (years) & $49 \pm 0.79$ & $49 \pm 0.65$ & NS \\
\hline Tumor size $(\mathrm{cm})$ & $2.5 \pm 0.07$ & $1.9 \pm 0.06$ & $<0.0001^{*}$ \\
\hline \multicolumn{3}{|l|}{ Extent of resection } & 0.171 \\
\hline Gross total resection & $176(39)$ & $279(61)$ & \\
\hline Near total resection & $37(49)$ & $39(51)$ & \\
\hline Subtotal resection & $42(45)$ & $51(55)$ & \\
\hline \multicolumn{3}{|l|}{ Approach } & $<0.011 *$ \\
\hline Middle cranial fossa & $45(33)$ & $91(67)$ & \\
\hline Retrosigmoid & $58(36)$ & $103(64)$ & \\
\hline Translabyrinthine & $152(46)$ & $175(54)$ & \\
\hline \multicolumn{3}{|l|}{ Cyst } & NS \\
\hline Yes & $21(41)$ & $30(59)$ & \\
\hline No & $234(41)$ & $339(59)$ & \\
\hline \multicolumn{3}{|c|}{ Neurofibromatosis-2 (NF2) } & NS \\
\hline Yes & $15(50)$ & $15(50)$ & \\
\hline No & $240(40)$ & $354(60)$ & \\
\hline
\end{tabular}

$* P<0.05, N S$ not significant

Table 2 Results of univariate analysis demonstrating the effect of tumor size and surgeon on facial nerve palsy

\begin{tabular}{lll}
\hline$N=624$ & \multicolumn{2}{l}{ Facial nerve palsy } \\
\cline { 2 - 3 } & Yes $(\%)$ & No $(\%)$ \\
\hline Extracanalicular tumor diameter $(\mathrm{cm})$ & \\
$\leq 1.0$ & 24 & 76 \\
$1.1-2.0$ & 37 & 63 \\
$2.1-3.0$ & 48 & 52 \\
$>3.0$ & 56 & 44 \\
Surgeon & & \\
1 & 43 & 57 \\
2 & 38 & 62 \\
\hline
\end{tabular}

function, $P=\mathrm{NS}$; Table 1), and this remained an insignificant predictor of outcome in the multivariate model (Table 3).

The effect of size on facial nerve preservation

As expected, the mean tumor size was higher for patients with post-operative facial nerve palsy than for those with normal facial nerve functioning $(2.5 \pm 0.07 \mathrm{~cm}$ vs. $1.9 \pm 0.06 \mathrm{~cm}$, respectively, $P<0.0001$; Table 1). Given that there was a statistically significant difference in tumor size between patients who had facial nerve palsy and those with normal facial nerve function, we performed univariate analysis based on three ranges for tumor sizes (Table 2). On multivariate analysis, tumor size predicted facial nerve palsy even when extent of resection and surgical approach were included in the regression model for patients followed $\geq 6$ and $\geq 12$ months (OR 1.27, 95\% CI 1.09-1.49, $\bar{P}<0.01$; OR $1.35,95 \%$ CI $1.10-1.67, P<0.01$; Table $3 \mathrm{a}$ and $b$, respectively).

The effect of extent of resection on facial nerve preservation

Gross total resection (GTR) was performed in 455 (73\%) of 624 patients, NTR was performed in 76 patients (12\%), and STR was performed in 93 patients $(15 \%)$. There was no statistical difference $(P=0.171)$ between extent of resection and facial nerve preservation (Table 1) on univariate analysis, and NTR and STR did not alter facial nerve outcomes when tumor size was included in the multivariate regression model for patients followed $\geq 6$ and $\geq 12$ months. Similarly, GTR was not associated with increased facial nerve palsy when controlling for tumor size.

The effect of surgical approach on facial nerve preservation

The middle cranial fossa approach was performed in 136 (22\%) of 624 patients, the retrosigmoid approach was performed in 161 patients $(26 \%)$, and the translabyrinthine approach was performed in 327 patients $(52 \%)$. There was no statistically significant relationship $(P=0.010)$ between the surgical approach and facial nerve palsy on either univariate (Table 1) or multivariate analysis for patients followed $\geq 6$ and $\geq 12$ months.

The learning curve of facial nerve preservation

Table 4 depicts facial nerve preservation rates as a function of year of neurosurgeon experience. As seen in Table 4, that while between-year rates of facial nerve palsy vary significantly, in general, facial nerve preservation were lower in the first 2 years of VS surgical practice, and improved slightly over time.

\section{Discussion}

The risk of facial nerve palsy after microsurgical removal of VS cannot be entirely eliminated, even with refinements in surgical technique. Thus, surgical resection of these 
Table 3 (a) Results of the multivariate analysis demonstrating the odds ratio and confidence intervals for rate of facial nerve palsy when tumor size, extent of resection and surgical approach are included in the regression model facial outcomes at 6 months and (b) multivariate analysis limited to facial outcome at 12 months

\begin{tabular}{|c|c|c|c|c|}
\hline & \multirow[t]{2}{*}{ OR } & \multicolumn{2}{|c|}{ Facial nerve palsy $95 \%$ CI } & \multirow[t]{2}{*}{$P$-value } \\
\hline & & - & + & \\
\hline \multicolumn{5}{|c|}{ (a) $\geq 6$ months follow-up $(N=624)$} \\
\hline \multicolumn{5}{|l|}{ Tumor size $(\mathrm{cm})$} \\
\hline Per $0.1 \mathrm{~cm}$ & 1.27 & 1.09 & 1.49 & $<0.01$ \\
\hline \multicolumn{5}{|l|}{ Extent of resection } \\
\hline Near Total resection & 1.23 & 0.71 & 2.17 & 0.70 \\
\hline Subtotal resection & 1.05 & 0.66 & 1.67 & 1.19 \\
\hline \multicolumn{5}{|l|}{ Surgical approach } \\
\hline Retrosigmoid & 0.80 & 0.66 & 1.14 & 0.19 \\
\hline Translabyrinthine & 1.04 & 0.66 & 1.64 & 1.14 \\
\hline \multicolumn{5}{|c|}{ (b) $\geq 12$ months follow-up $(N=400)$} \\
\hline \multicolumn{5}{|l|}{ Tumor size $(\mathrm{cm})$} \\
\hline Per $0.1 \mathrm{~cm}$ & 1.35 & 1.10 & 1.67 & $<0.01$ \\
\hline \multicolumn{5}{|l|}{ Surgical approach } \\
\hline Retrosigmoid & 0.93 & 0.63 & 1.36 & 0.705 \\
\hline Translabyrinthine & 0.79 & 0.55 & 1.15 & 0.223 \\
\hline
\end{tabular}

Table 4 Facial nerve outcomes expressed as a function of years of surgeon experience

\begin{tabular}{|c|c|c|}
\hline Surgeon year & $n$ & $\begin{array}{l}\text { Percentage facial } \\
\text { nerve preservation }\end{array}$ \\
\hline 1 & 16 & 50 \\
\hline 2 & 25 & 52 \\
\hline 3 & 20 & 60 \\
\hline 4 & 12 & 50 \\
\hline 5 & 9 & 44 \\
\hline 6 & 20 & 70 \\
\hline 7 & 24 & 71 \\
\hline 8 & 26 & 77 \\
\hline 9 & 29 & 66 \\
\hline 10 & 30 & 57 \\
\hline 11 & 30 & 63 \\
\hline 12 & 22 & 45 \\
\hline 13 & 40 & 45 \\
\hline 14 & 45 & 62 \\
\hline 15 & 43 & 56 \\
\hline 16 & 45 & 51 \\
\hline 17 & 47 & 53 \\
\hline 18 & 51 & 63 \\
\hline 19 & 36 & 64 \\
\hline 20 & 31 & 71 \\
\hline 21 & 23 & 65 \\
\hline
\end{tabular}

tumors is associated with significant risk of physical, cosmetic, and psychological morbidity associated with significant facial nerve palsy $[8,23]$. Previously, in a systematic review of the literature, we focused on factors associated with reported rates of facial nerve function in a large population of 11,873 patients treated VS, and found that patients with larger tumors were less likely to have preserved facial nerve function after surgery than patients with smaller tumors $(\leq 2.0 \mathrm{~cm} 90 \%$ vs. $>2.0 \mathrm{~cm} 67 \%$, $P<0.0001$ ) [12].

In this study, we examined facial nerve function in 624 patients undergoing VS surgery at our institution and found that tumor size is the most important predictor of facial nerve outcome, and that age, extent of resection and surgical approach do not independently predict facial palsy. This finding replicates the results of our previous systemic review.

The facial nerve can usually tolerate a large degree of stretching, compression or distortion without apparent facial palsy $[19,24]$. However, as the tumor grows, the nerve comes under even greater tension, which increases the likelihood of stretch injury, and this may explain the high rate of facial palsy seen in patients with large tumors $[19,24]$. Facial nerve dysfunction may also result from poor vascularization of nerve segments that are effaced by large tumors [19, 24]. While larger tumors pose greater risk to the nerve; however, tumor size alone cannot predict the degree of adhesiveness, or the difficulty of dissection [18, 19], suggesting that other factors also impact facial nerve outcome. The facial nerve can traverse any part of the tumor capsule and even pass through the tumor itself, a feature that occurs equally in small and large tumors [15]. Thus, additional methods for pre-operative assessment of these patients may be needed to improve surgical outcomes.

The lack of benefit we observed with less aggressive resection deserves additional discussion. Our STRs were not planned, and it is interesting to speculate that an approach of intentional STR might be warranted in many 
cases. The concept of intentional STR or STR based on intra-operative findings might represent the future of VS surgery, and is certainly worthy of further study. The cases that were subtotal or NTR relate to factors such as thinning of the facial nerve or adherent vessel loops that preclude safe removal of tumor. Thus, while our data do not prove hypothesis that STR of large VS is superior to GTR, our consideration of these findings have changed our practice, and led us to plan STR's in more difficult cases, stopping earlier, and treating the residual fragment with radiosurgery post-operatively. Time will tell whether this is the best way to improve facial nerve outcomes in these patients.

Further, while there may be a small difference in facial nerve outcomes between patients receiving GTR and STR, our analysis suggests that it may take a large study to demonstrate this benefit. We performed a power analysis and found that to demonstrate the $8 \%$ between group difference demonstrated in this study with $80 \%$ power and $\alpha=0.05$ would require 454 patients per group. We think such an effort would take several centers many years to demonstrate.

In conclusion, because facial palsy is a debilitating and psychologically devastating condition for the patient, we suggest altering surgical aggressiveness in patients with unfavorable tumor anatomy, particularly in cases with large tumors. It has been shown in the literature that neuromonitoring during VS resection can be an effective approach to preserve facial nerve function, although it has limited ability to predict the extent or rate of recovery in cases of abnormal function [14, 25-28]. With large tumors, residual disease can be followed and controlled with radiosurgery if interval growth is noted $[3,15]$.

Acknowledgment Dr. Parsa is supported, in part, by the Reza and Georgianna Khatib endowed chair in skull base tumor surgery. Dr. Sughrue is supported by the Neurosurgery Research \& Education Foundation grant from the American Association of Neurological Surgeons (AANS NREF). Mr. Rutkowski is supported by the Doris Duke foundation. Mr. Kane is supported by the Howard Hughes Medical Foundation and the Ivy Foundation. We would like to thank our neuro-otology Steven Cheung, M.D. and Lawrence Lustig, M.D. for their help performing these operations.

Financial disclosure The authors declare that they are not involved in any relationships with companies that make products related to this study.

Open Access This article is distributed under the terms of the Creative Commons Attribution Noncommercial License which permits any noncommercial use, distribution, and reproduction in any medium, provided the original author(s) and source are credited.

\section{References}

1. Sughrue ME, Yeung AH, Rutkowski MJ, Cheung SW, Parsa AT (2009) Molecular biology of familial and sporadic vestibular schwannomas: implications for novel therapeutics. J Neurosurg. doi: 10.3171/2009.10.JNS091135

2. Yeung AH, Sughrue ME, Kane AJ, Tihan T, Cheung SW, Parsa AT (2009) Radiobiology of vestibular schwannomas: mechanisms of radioresistance and potential targets for therapeutic sensitization. Neurosurg Focus 27:E2

3. Sughrue ME, Yang I, Aranda D, Lobo K, Pitts LH, Cheung SW, Parsa AT (2009) The natural history of untreated sporadic vestibular schwannomas: a comprehensive review of hearing outcomes. J Neurosurg 112:163-167

4. Yang I, Aranda D, Han SJ, Chennupati S, Sughrue ME, Cheung SW, Pitts LH, Parsa AT (2009) Hearing preservation after stereotactic radiosurgery for vestibular schwannoma: a systematic review. J Clin Neurosci 16:742-747

5. Yang I, Sughrue ME, Han SJ, Aranda D, Pitts LH, Chennupati S, Cheung SW, Parsa AT (2010) A comprehensive analysis of hearing preservation after radiosurgery for vestibular schwannoma. J Neurosurg 112:851-859

6. Yang I, Sughrue ME, Han SJ, Fang S, Aranda D, Cheung SW, Pitts LH, Parsa AT (2009) Facial nerve preservation after vestibular schwannoma gamma knife radiosurgery. J Neurooncol 93:41-48

7. Samii M, Gerganov V, Samii A (2006) Improved preservation of hearing and facial nerve function in vestibular schwannoma surgery via the retrosigmoid approach in a series of 200 patients. J Neurosurg 105:527-535

8. Samii M, Matthies C (1997) Management of 1000 vestibular schwannomas (acoustic neuromas): hearing function in 1000 tumor resections. Neurosurgery 40:248-260, discussion 260-262

9. Samii M, Matthies C, Tatagiba M (1997) Management of vestibular schwannomas (acoustic neuromas): auditory and facial nerve function after resection of 120 vestibular schwannomas in patients with neurofibromatosis 2. Neurosurgery 40:696-705, discussion 705-706

10. Samii M, Tatagiba M, Matthies C (1992) Acoustic neurinoma in the elderly: factors predictive of postoperative outcome. Neurosurgery 31:615-619, discussion 619-620

11. Sughrue ME, Yang I, Aranda D, Lobo K, Pitts LH, Cheung SW, Parsa AT (2010) Facial nerve preservation after vestibular schwannoma gamma knife radiosurgery. J Neurooncol 112: 163-167

12. Sughrue ME, Yang I, Aranda D, Rutkowski MJ, Fang S, Cheung SW, Parsa AT (2009) Beyond audiofacial morbidity after vestibular schwannoma surgery. J Neurosurg. doi: 10.3171/2009. 10.JNS091203

13. Sughrue ME, Yang I, Han SJ, Aranda D, Kane AJ, Amoils M, Smith ZA, Parsa AT (2009) Non-audiofacial morbidity after gamma knife surgery for vestibular schwannoma. Neurosurg Focus 27:E4

14. Arriaga MA, Luxford WM, Atkins JS Jr, Kwartler JA (1993) Predicting long-term facial nerve outcome after acoustic neuroma surgery. Otolaryngol Head Neck Surg 108:220-224

15. Ferri GG, Modugno GC, Pirodda A, Fioravanti A, Calbucci F, Ceroni AR (2008) Conservative management of vestibular schwannomas: an effective strategy. Laryngoscope 118:951-957

16. Marouf R, Noudel R, Roche PH (2008) Facial nerve outcome after microsurgical resection of vestibular schwannoma. Prog Neurol Surg 21:103-107

17. Coca Pelaz A, Fernandez Lisa C, Gomez JR, Rodrigo JP, Llorente JL, Suarez C (2008) Complete facial palsy following surgery for acoustic nerve neurinoma: evolution and associated ophthalmological complications. Acta Otorrinolaringol Esp 59: 223-227

18. Lee J, Fung K, Lownie SP, Parnes LS (2007) Assessing impairment and disability of facial paralysis in patients with vestibular schwannoma. Arch Otolaryngol Head Neck Surg 133:56-60 
19. Veronezi RJ, Fernandes YB, Borges G, Ramina R (2008) Longterm facial nerve clinical evaluation following vestibular schwannoma surgery. Arq Neuropsiquiatr 66:194-198

20. House JW, Brackmann DE (1985) Facial nerve grading system. Otolaryngol Head Neck Surg 93:146-147

21. Hosmer DW, Lemeshow S (2000) Applied Logistic Regression. John Wiley, New York

22. Hosmer DW, Hjort NL (2002) Goodness-of-fit processes for logistic regression: simulation results. Stat Med 21:2723-2738

23. Sampath P, Holliday MJ, Brem H, Niparko JK, Long DM (1997) Facial nerve injury in acoustic neuroma (vestibular schwannoma) surgery: etiology and prevention. J Neurosurg 87:60-66

24. Fenton JE, Chin RY, Fagan PA, Sterkers O, Sterkers JM (2002) Predictive factors of long-term facial nerve function after vestibular schwannoma surgery. Otol Neurotol 23:388-392
25. Fukuda M, Oishi M, Takao T, Saito A, Fujii Y (2008) Facial nerve motor-evoked potential monitoring during skull base surgery predicts facial nerve outcome. J Neurol Neurosurg Psychiatry 79: 1066-1070

26. Isaacson B, Kileny PR, El-Kashlan H, Gadre AK (2003) Intraoperative monitoring and facial nerve outcomes after vestibular schwannoma resection. Otol Neurotol 24:812-817

27. Myrseth E, Moller P, Pedersen PH, Lund-Johansen M (2009) Vestibular schwannoma: surgery or gamma knife radiosurgery? A prospective, nonrandomized study. Neurosurgery 64:654-661, discussion 661-663

28. Neff BA, Ting J, Dickinson SL, Welling DB (2005) Facial nerve monitoring parameters as a predictor of postoperative facial nerve outcomes after vestibular schwannoma resection. Otol Neurotol $26: 728-732$ 